\title{
Design and Delivery of an Electro-Optics Summer Camp for Secondary Stu- dents (P12 Resource/Curriculum Exchange)
}

\section{Dr. Benjamin R. Campbell, Robert Morris University}

Ben Campbell holds a BS in physics and MS in electrical engineering from Penn State and a PhD in engineering from Robert Morris University. For the first decade of his career, he worked as a laser engineer at the Penn State Electro-Optics Center. In 2011 he joined Robert Morris University and currently holds the rank of Associate Professor of Engineering. He has been supporting RMU's mechatronics minor and also teaching dynamics and electronics classes. Recently he has been awarded research grants to study the laser welding of plastics and assist with commercialization of the technology. Since 2005, Dr. Campbell has served as faculty for the Pennsylvania Governor's School for the Sciences (a summer program at Carnegie Mellon) and currently sits on the Board of Directors for the PGSS Campaign, a nonprofit that is responsible for raising the funds to finance and sustain the program. He also serves on his local school board. 


\title{
Design and Delivery of an Electro-Optics Summer Camp for Secondary Students (P12 Resource/Curriculum Exchange)
}

\begin{abstract}
A one week summer camp was designed to introduce middle and high school students to electro-optics. The camp is a combination of lecture, labs, games, and student driven projects. Each day there are short lectures introducing topics of electro-optics (photons, properties of light, electricity, basic circuits, mechatronics). Every lecture is followed by an activity that relates to the lecture topics. The camp has been refined over six summers to result in students learning enough to build Arduino driven optical and mechanical devices to produce a laser light show. The students gain both the hardware and software skills to control sources of light and mechanically drive mirrors, beam splitters, diffraction gratings and other optical devices. Supplemental activities are also introduced to help with differentiation to keep high performing students engaged while students who may need additional time can complete their tasks. Students are encouraged to demonstrate their creations for the class. This format could easily be replicated and offered with minimal investment in equipment and resources.
\end{abstract}

\section{Background}

Electro-optics (also commonly called photonics) is the study of light and electricity. Specifically it concerns the devices that generate and propagate light, which are often controlled by electrical systems. Electro-optics encompasses lasers, fiber optics, liquid crystals, sensors, optical materials, light emitting diodes, transmitters, receivers and a multitude of other devices. Military applications of electro-optics alone are a $\$ 10 \mathrm{~B}$ industry, projected to grow to $\$ 15 \mathrm{~B}$ over the next ten years [1]. Military and Defense spending on electro-optics are only about $25 \%$ of the electro-optics market [2]. This US Bureau of Labor and Statistics labels photonics engineers as Standard Occupation Classification (SOC) code \# 17-2199.07 and groups them under the heading "Engineering, Other" which is a segment with a projected job growth of 5-9\% annually [3]. The reports for average pay for an electro-optical engineer vary between to $\$ 90,000$ to $\$ 100,000$ per year $[4,5]$. This is a growing industry with ample job prospects for students who elect to pursue degrees related to electro-optics.

With the low cost of Arduinos and similar micro controllers, it is very easy to teach students at a young age basic coding and electrical wiring. The simple program tutorials from sites that share Arduino examples (like Arduino.cc [6] and Adafruit.com [7]) can serve as a starting point for class examples and then prompt students to make changes to the code or combine two or more programs together.

For the past six years, a one-week summer camp has been offered by Robert Morris University's School of Engineering, Mathematics, and Science in 4-5 day formats, at 5-6 hours long and includes lunch for the students in grades 7-12. It is run with one professor and 1-2 
college engineering students assisting. The advertisements for the camp (Figure 1) have described it in this way:

"Electro-optics technology surrounds us, hidden from the untrained observer. The touch screen on a smart phone, an ultraviolet laser that reads data from a DVD, internet information streaming across the globe on fiber optics cables; these are all electro-optic based technologies. In this camp, students will learn the basic principles of electronics and learn how to use engineering tools like multimeters, function generators, oscilloscopes, breadboards and circuit design software to control lights, motors, and sensors. No required background in physics or electronics is necessary."

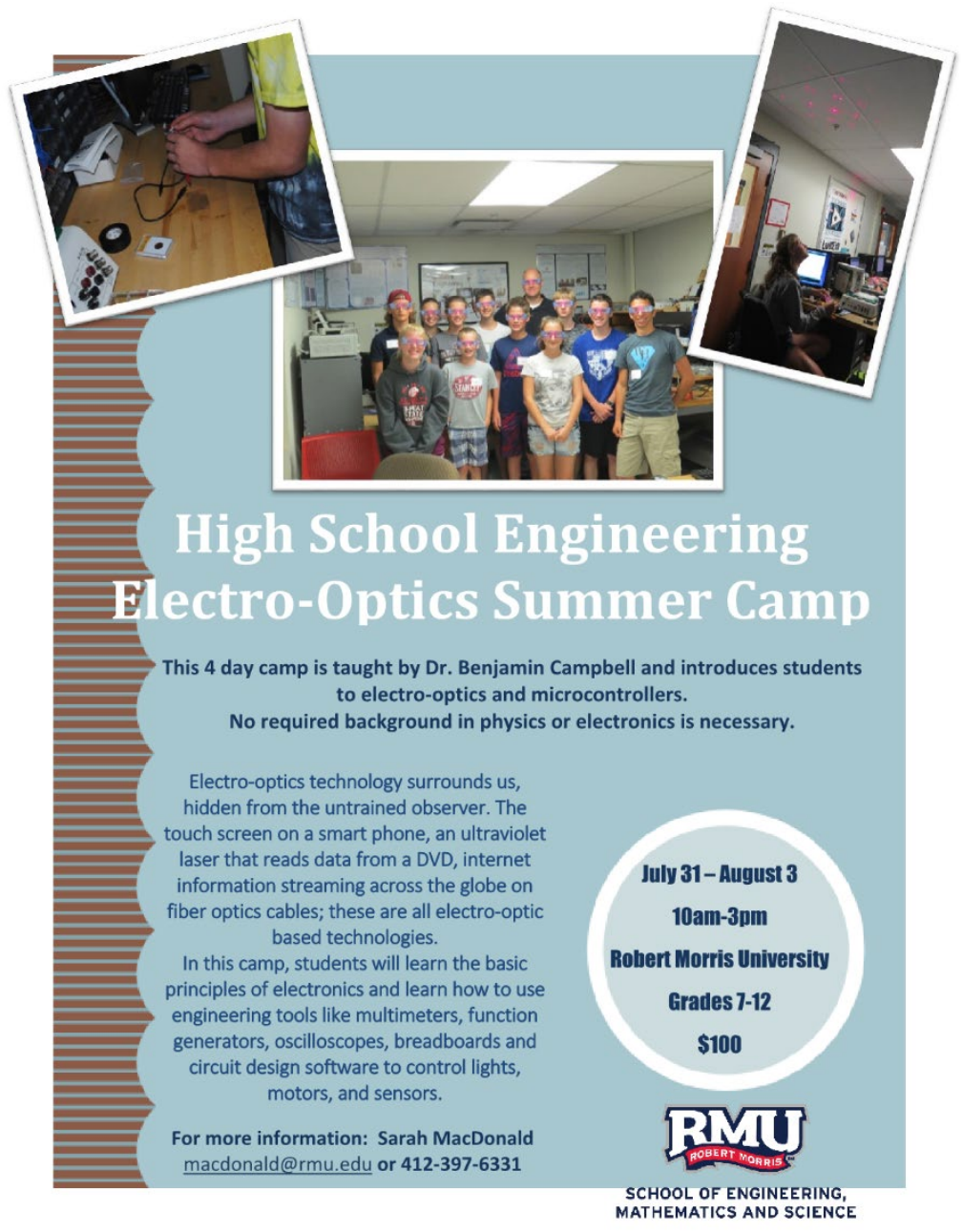

Figure 1. The 2018 Advertisement for the RMU Electro-Optics Camp

In the first two years offering the camp, there were only 4-5 students enrolled. In the subsequent four years the enrollment has been 10-12 students and there has been a waiting list for attending. The camps size has been capped at a dozen students, mainly due to lab space limitations. The grades have been fairly normally distributed with most students attending going 
into $8^{\text {th }}-10^{\text {th }}$ grade (Figure 2). The fee for attending has ranged from $\$ 100-150$ for the week. One year a grant covered free admission for all of the participants.

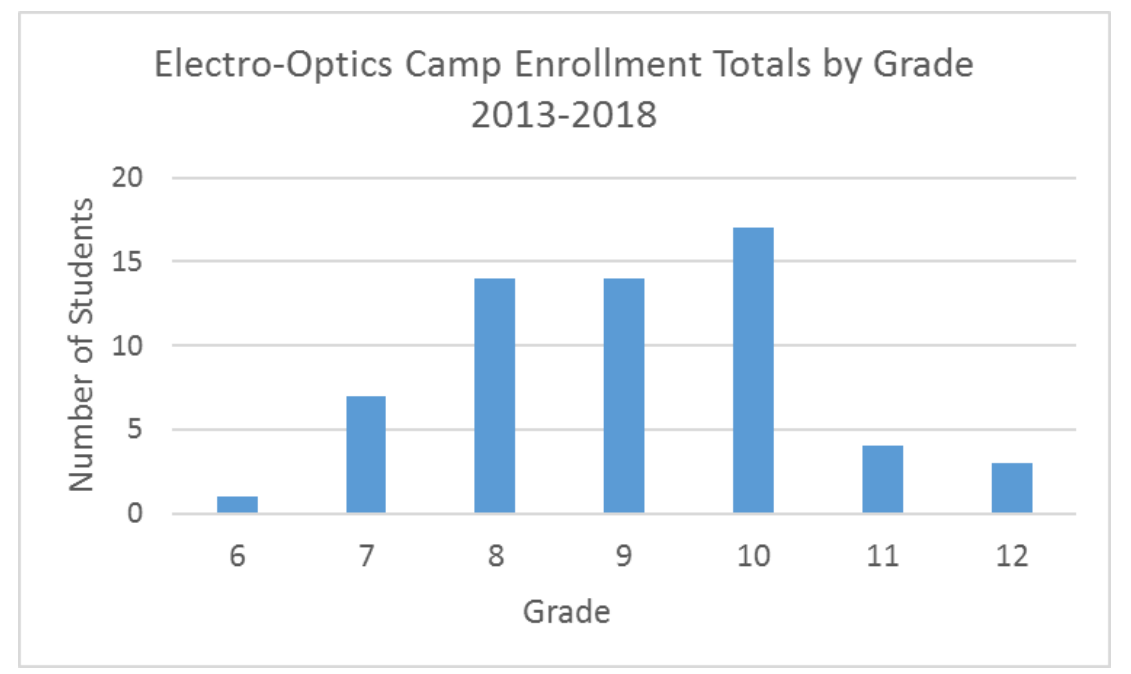

Figure 2. Grade distribution of summer camp participants over 6 years

\section{Curriculum Design and Delivery}

The summer camp is divided into four days, each day includes some brief lecture topics, a demonstration of a lab concept, students completing an activity, and freedom for exploration of the topic. Resources have been added to the camp each summer; the items currently used for instruction are listed below followed by a narrative of the daily curriculum.

\section{Materials Needed}

- Computer workstations with Arduino IDE and NI Multisim

- NI ELVIS board (or similar device) or a multimeter, variable power supply, function generator and oscilloscope for each workstation

- Breadboard, wire kits, resistors, potentiometers, transistors, diodes, LEDs, and Laser diodes with wire leads

- Photoreceiver or photoresistor

- Laser pointers (preferably an assortment of red, green and purple)

- Fiber optic cables

- Diffraction grating glasses

- Arduinos with USB cables

- Servo motors, DC Motors

- Speakers

- Tape, Hot Glue, and general construction materials.

- Laser Chess, Laser Maze

- Spectra Sound Kit, or similar [8] 


\section{Day 1}

At the start of the summer camp it is useful to know the ages, abilities, and interests of the students. They are asked to share this information with the class.

Each student introduced themselves to the class by answering the following:

- Who are you? (name, grade, school)

- Why are you here?

- What are your hobbies/interests?

Then questions for the entire class at once, by a show of hands:

- How many have learned about Volts/Amps/Ohms in school?

- How many have used a multimeter?

- How many have used an Oscilloscope?

The instructor introduces themselves and talks about the basics of electro-optics by starting with the concept of a photon and expanding to the entire electro-magnetic spectrum. Pass out diffraction grating glasses and show them the spectrum using a white light source. Then explains the concept of a laser starting with the three properties which differentiate a laser from a light source (monochromatic, coherent and highly collimate). Use the diffraction grating glasses to confirm that a laser is monochromatic. The discussion is then transitioned to electricity with an explanation of voltage, current and resistance framed around Ohm's Law. Describe the flow of electrons as current. What pushes the electrons? (electric potential known as voltage) What opposes electron flow? (resistance) Explain basics of conductors and insulators and have them give examples.

Each student or pair of students will need a computer for the next part of the lesson. Using Multisim, the National Instruments Circuit Design Suite, demonstrate a simple circuit with a DC voltage source and resistor and show how a multimeter can be attached to read voltage and current. Students will work along on their own computers building the basic circuit, then will adjust the voltage and see how the current reacts. Then using the "3D_Virtual Library", an LED can be added that appears as an actual LED in the virtual circuit. Students can add switches, more LEDs and try different wiring configurations until they are comfortable simulating basic wiring diagrams. Make note of the polarity of the LED to the students.

Next the students will begin building actual circuits similar to the ones they simulated. Use a multimeter to demonstrate continuity checks, and even test some materials around the room referring back to the earlier discussion about resistance, conductors and insulators. Then explain the breadboard and have the students use multimeters in the continuity setting to explore the board and explain which holes are connected under the surface. Have the groups compare results and see if they all agree. Then walk them through building an actual circuit on the breadboard with a resistor, LED and external variable power source. Have the students test the 
variable power source with the multimeter to see the range of voltages and give them guidelines for maximum voltage. If time permits explain series and parallel and have them place LEDs in series and parallel to see the effects on brightness with each configuration. Reserve some time at the end of the day to teach the two player game "Laser Chess" and one player logic game "Laser Maze" (Figure 3) and give the students a chance to play. Use Laser games on any day when the lesson runs short or some of the students work faster than expected.

Goals by end of day 1: Know difference between V, I, and R. Be able to use a multimeter. Know how a breadboard is configured. Introduce Multisim and circuit building on breadboards. Play Laser Chess/Maze to become comfortable with tracing beam paths.

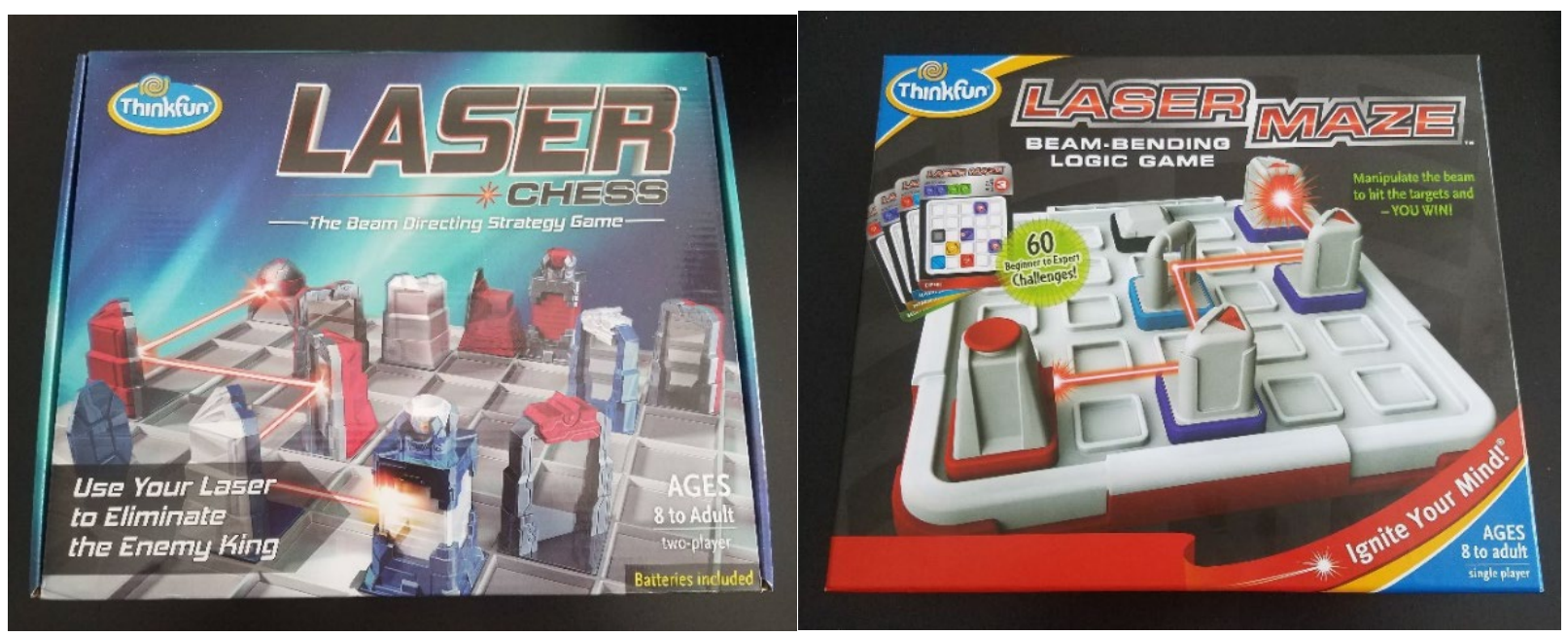

Figure 3. Laser based games (Laser Chess ${ }^{T M}$ and Laser Maze ${ }^{T M}$ ) teach reflection, beam splitting, ray tracing and the visualization of optical paths.

\section{Day 2}

Begin the day with lessons on lasers, explaining the concept of "Light Amplification by Stimulated Emission of Radiation" and talk about the construction of different types of lasers. Introduce the concept of fiber optics and teach refraction and total internal reflection. Do demos of laser light being carried through a fiber. Let the students get hands on with the fibers and laser sources.

Review previous day's electrical topics. Present new electrical topics, describing the difference between DC and AC signals. Introduce wave properties (concepts of amplitude, period, frequency, wavelength, and phase). Demonstrate creating waves with a waveform or function generator and observing them with an oscilloscope. Connect the wave properties with visualization of the waves. Let the students explore sending and viewing waves and taking measurements of waves.

Have the students build a circuit with an LED and resistor $(220 \mathrm{ohm})$ powered by the function generator and figure out the amplitude and frequency that can make the light appear 
flickering. Have them drive the frequency higher until the light appears continuous. See if they can determine our visual frame rate limit.

Give each student a speaker and have them wire the function generator to the speaker and oscilloscope. Have the students experiments with making sound from the speaker using the function generator and make sure they can also see it on the oscilloscope. Explain how the speaker works. Give them time to freely experiment with circuit building on the board with these components.

Introduce the Arduino at the end of the day. Walk through software installation if needed on the workstations, explain what the Arduino is and the basic code structure. Have them load the "blink" program from the example and have it drive the LED in their breadboard, also have them wire up a laser diode use the same program to drive the laser. Have students wear diffraction grating glasses and observe the LED and laser. With any remaining time, have students play Laser Chess or Laser Maze.

Goals by end of day 2: Understand waves, function generators and oscilloscopes. Understand the effects of the properties of an AC signal when driving lights or sound. Be able to run a basic program on an Arduino to make an LED/laser blink.

\section{Day 3}

Start with a laser presentation to talk about high power and ultrashort pulse lasers and their unique applications in manufacturing, communications, medicine, and more.

Review the previous day's discussion of optical fibers. Use fiber optics samples and prisms to show refraction and total internal reflection, then demonstrate again the fiber optics, but with a light source and receiver attached. Give students an LED source and photo receiver with the optical fiber and demonstrate how to connect them (special couplers can be acquired, or just tape the fiber onto the LED and photo receiver). Have the students pulse the LED signal and see the received signal at the other end of the fiber. Observe it on the oscilloscope to demonstrate long distance optical communication systems. Have them compare input and output signals of different shapes and frequencies. Perform a demonstration encoding music on a laser beam and show wireless transmission of the sound via laser beam to a distant receiver and reconstitute it through an amplified speaker using the Spectra Sound Kit or a similar type of device. Interfere with the beam and have the students observe the effects; run it through sunglasses to hear the amplitude (loudness) decrease run it through a diffraction grating or beam splitter and show how each spot now carries the original sound signal (but at lower amplitude). Students can attempt to set up mirrors from the laser game to get the laser from the source to the receiver wirelessly but bounced off several surfaces.

Continue the Arduino work. Have them work in pairs to practice how to write and upload code. Make sure each student can send basic code to light the LED. Have them experiment with programming light patterns. Give them breadboards, LEDs, lasers, and resistors 
to play with, have some simple examples for them to try to get better acclimated to Arduino programming. Introduce servo motors and have them control motion position and direction. Advanced students can use a potentiometer or photo-resistor to control the motor using the example "knob" program. Advanced students may opt to work individually depending on experience and comfort level. If time permits, introduce four-lead multicolor LEDs and teach them how to use the code to mix colors.

Goals by end of day 3: Understand laser data transmission. Be able to make or edit simple Arduino programs to control lights, lasers, sound and motors.

\section{Day 4}

Begin with presenting more applications of electro-optics with topics such as laser eye surgery, laser welding, laser weapons, optical tweezers, and more.

Final Project: Students have the remainder of the day to explore and build a project. Have the students combine diffraction gratings, lasers, LEDs, sensors, motors and cheap construction materials (LEGO, straws, tape, foil, toothpicks) to make an Arduino powered laser light show sequence or a robot, or anything else they want to create. They can also play laser games in their free time. Have students demonstrate their projects to each other throughout the day as they complete milestones on their projects. Challenge them to improve upon the design with more sophisticated code or additional devices added into their project.

Goals by end of day 4: Be able to make an Arduino powered light display incorporating LEDs, lasers, motors, diffraction gratings, potentiometers, photo resistors, speakers, or anything else they can imagine adding with the time and resources available. Have the students demonstrate achievements throughout the day to generate ideas for peers and inspire more advanced designs.

\section{Assessment Instrument}

Starting in 2018, a pre and post survey was administered in the summer camp. Students were given a series of statements about their inclinations towards STEM as a path in college and a career. A series of yes/no questions were used to learn how many students have done similar work before and which projects were new learning experiences to them. We expected the student entering the camp already had high interest in STEM in school and for a career, what we did not know is whether the camp activities would be novel for them, or redundant from other similar educational activities.

This prompt was given:

"Thank you for participating in our summer camp. We hope that you enjoy(ed) the camp and will have (had) an informative time. To help us organize more exciting events in the future, we would like your opinion regarding this camp. This survey is voluntary, and your responses will be kept anonymous. The survey results will be used to study the effectiveness of this camp." 


\begin{tabular}{|c|c|c|c|c|}
\hline & $\begin{array}{l}\text { STEM = Science, Technology, Engineering } \\
\text { and Mathematics }\end{array}$ & Agree & $\begin{array}{l}\text { No } \\
\text { Opinion }\end{array}$ & Disagree \\
\hline 1 & $\begin{array}{l}\text { I have a strong interest in pursuing a } \\
\text { STEM-related career. }\end{array}$ & & & \\
\hline 2 & $\begin{array}{l}\text { I have a strong interest in } \\
\text { engineering. }\end{array}$ & & & \\
\hline 3 & $\begin{array}{l}\text { I have a strong interest in majoring in a } \\
\text { STEM field in College. }\end{array}$ & & & \\
\hline 4 & $\begin{array}{l}\text { I have a basic understanding of } \\
\text { engineering. }\end{array}$ & & & \\
\hline 5 & $\begin{array}{l}\text { I am interested in majoring in } \\
\text { engineering in college. }\end{array}$ & & & \\
\hline 6 & I am interested in engineering. & & & \\
\hline 7 & $\begin{array}{l}\text { I have a basic understanding of } \\
\text { electro-optics. }\end{array}$ & & & \\
\hline \multicolumn{2}{|r|}{$\begin{array}{l}\text { For the following, include your experiences } \\
\text { this week in camp when responding. (this } \\
\text { is shown in the post survey only) }\end{array}$} & Yes & No & \\
\hline 8 & $\begin{array}{l}\text { Have you ever used diffraction } \\
\text { gratings to study the color spectrum } \\
\text { of light sources? }\end{array}$ & & & \\
\hline 9 & $\begin{array}{l}\text { Have you ever built electronic } \\
\text { circuits before? }\end{array}$ & & & \\
\hline 10 & $\begin{array}{l}\text { Have you ever programmed an } \\
\text { Arduino before? }\end{array}$ & & & \\
\hline 11 & $\begin{array}{l}\text { Have you ever used a laser with } \\
\text { mirrors and motors to create a light } \\
\text { show? }\end{array}$ & & & \\
\hline
\end{tabular}

Figure 4. Pre and Post Survey given to camp students in 2018

\section{Results}

In the early years of the camp, each portion of each day was scripted and planned with designed activities. After assessing interest and response to each activity and the curiosity of the students, the activities were left more open ended and had multiple levels of depth so that advanced students could experiment while the lagging students achieved basic competency in the task. The final day is now planned as mostly creative free time for students to integrate all of the concepts they had learned into a final project that involved lights, lasers, sound and motion. Throughout the day students would show off their creations as they completed something interesting or unique (Figure 5). By encouraging demonstrations throughout the final day, the accomplishments and ingenuity of peers would generate creative ideas and variations on original designs that were student driven. For example, one student asked if we had any ping pong balls and we happened to have several in another lab. That student poked a hole in the ball and placed 
it over an LED to act as a diffuser which transformed a small bright light to a much larger glowing orb with a more pronounced visual effect. The other students were soon following suit and making their own LED displays with diffusers in different color schemes and configurations.

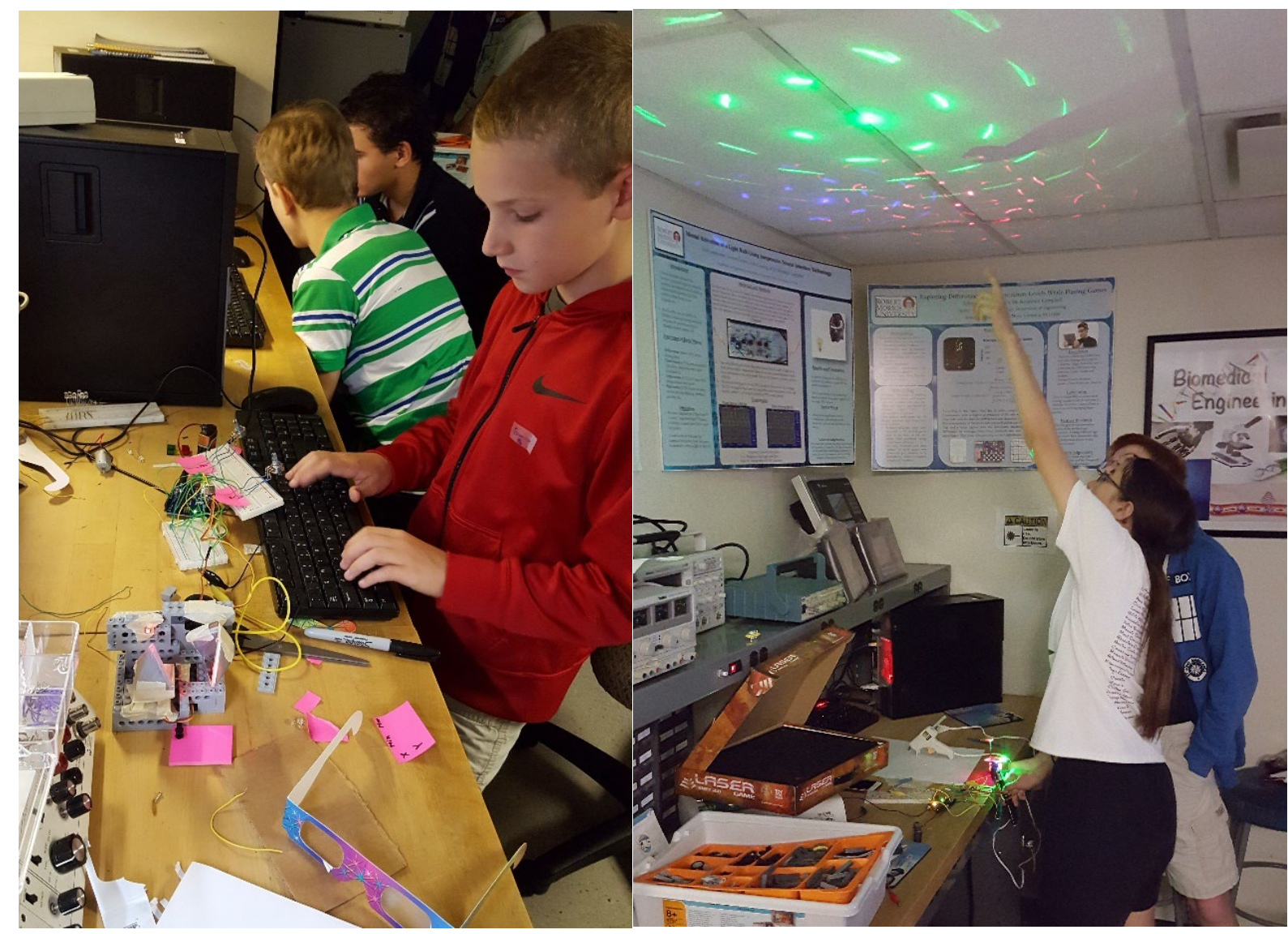

Figure 5. Students designed, built, and programmed laser shows using a combination of motors, mirrors, diffraction gratings, LEGO building blocks, tape and hot glue. (pictures used with permission)

Toward the end of the first day, the students were paired up and taught the game Laser Chess [9], which existed in similar forms in earlier versions under the names Deflexion, Khet and Khet 2.0 from the same creators. This game has been proven to have a complexity comparable to traditional chess [10]. There are competing variants to of this game like Optical Chess [11,12] and Laser Battle [13] (although Laser Battle may be harder to find after it lost a patent infringement lawsuit to the makers of Khet in 2009 [14]). Laser Chess utilizes the basic rules of optical reflection and allows students to practice ray tracing through a competitive strategy game. Some variations have an option to include beam splitters. If there are an odd number of students, or a student who prefers to play alone, Laser Maze [15] can be used to teach the same principles. It is a one person game that also uses mirrors and beam splitter but with a deck of cards with challenges of varying degrees of difficulty. Components are placed on the board to match the card's scenario by finding the right arrangement to achieve that particular beam start and finish locations. The purpose of Laser Maze and Laser Chess are twofold in 
summer camp; they teach the concepts of optical beam delivery, but they also provide an alternative educational activity for students who complete their design activities before others who may need more help. This allows differential instruction to provide additional help to those who are struggling, while the other students are still engaged in a relevant learning activity in the form of recreational play.

Games like Laser Chess have been popular among the students, some had even played it prior to the camp. If time allows, a tournament of laser chess can be organized and the winner from the summer camp can take home one of the games as the prize. One of the students had the idea to incorporate two mirrors from a Khet game into a 2-axis laser Galvonometer as seen in Figure 6. He was able to control the rotational position of each mirror by the Arduino and with proper alignment and programming he was able to code a laser show of basic geometric shapes on the wall. He adapted it to be hand driven by potentiometer knobs to steer the location of the beam, or could produce a pre-programmed show. Other students then also experimented with incorporating mirrors from the laser games into their systems.

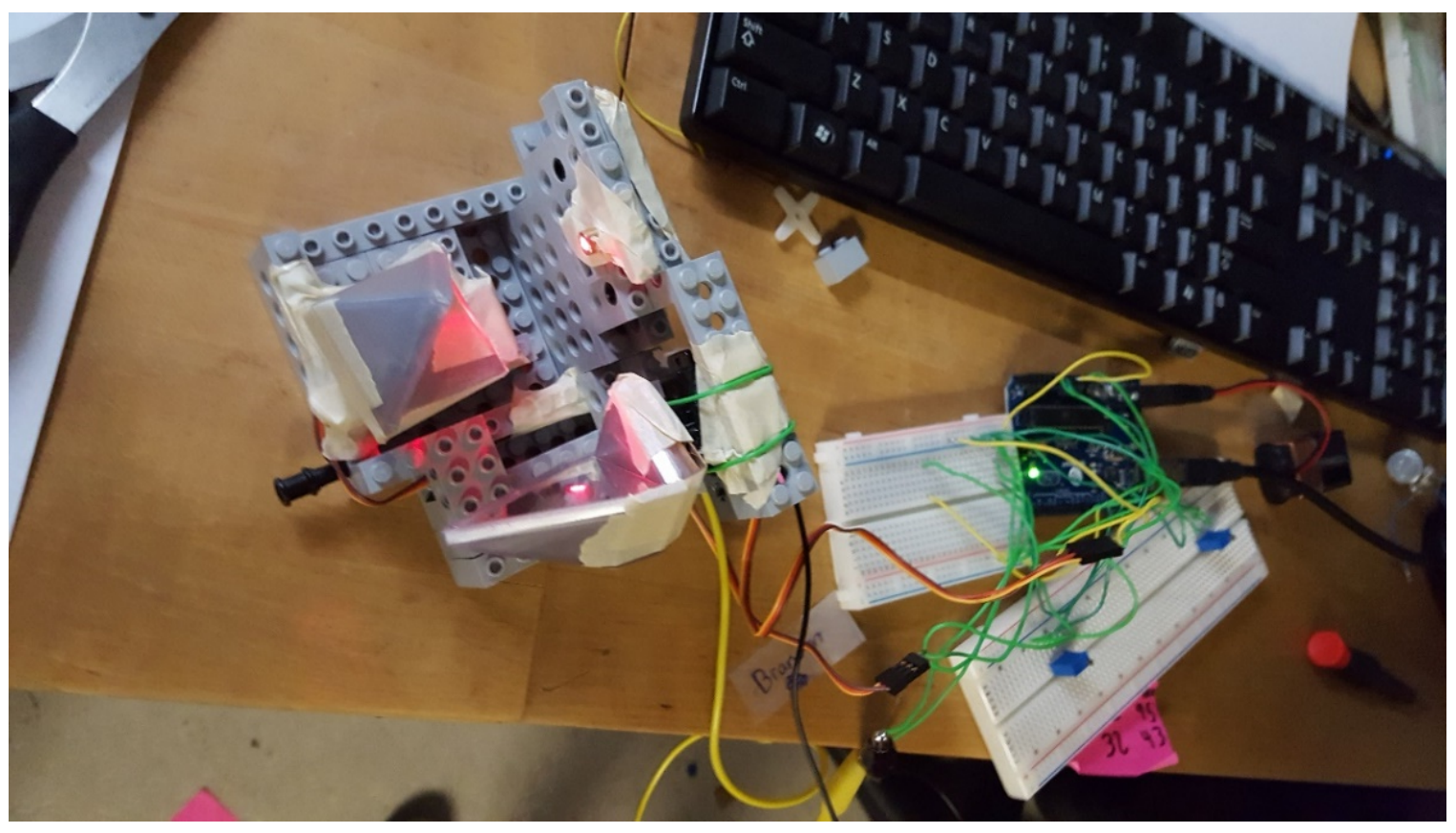

Figure 6. Laser Galvanometer designed and built by a $6^{\text {th }}$ grader using LEGO, two mirrors from the game Khet, two servo motors, and Arduino control for either pre-programmed laser motion or control of the $x-y$ position by two potentiometers

The pre-survey showed that most students had not done any STEM projects similar to the activities experienced in the camp. Most students came in with high interest levels in engineering so there wasn't much progress to be made. There were two categories that had a lower agreement rate than the others. For "I have a basic understanding of engineering" and "I have a basic understanding of electo-optics," the pre and post surveys showed an increase from $73 \%$ (pre) agreement to $91 \%$ (post). This showed that for the students who came with little knowledge of these two areas, they did feel more confident in understanding those fields after the 
camp. For the survey of previous experiences (Figure 7), few students had done anything like the electro-optics activities in this camp. The most common prior experience was building circuits with 9 out of 11 having a background and just under half having Arduino experience. One of the students was repeating the summer camp because he had enjoyed it so much the previous summer, so he added a slight bias to the results by marking that he had prior experience in all four tasks (which he did from the prior camp). In the post surveys, two students gave the exact same response to the skill set as they had in pre-survey (that they had only done one of the four activities prior). They had done all four activities in this camp and should have responded in the affirmative so it is likely that that did not read the survey closely to realize they should have included their camp experience in their response.

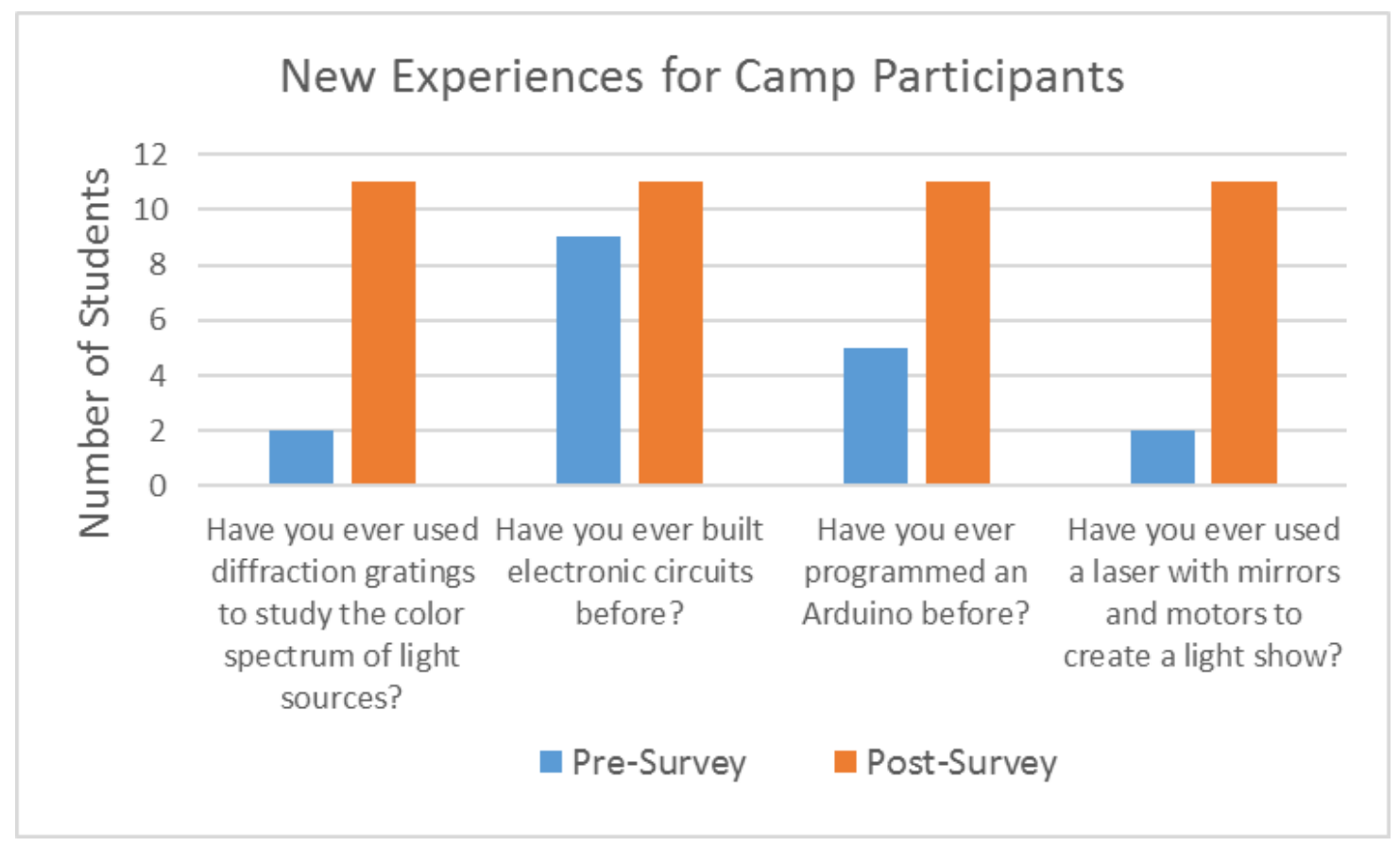

Figure 7. Results from survey implemented in 2018 with $n=11$ respondents to assess prior experience with any of the main camp activities.

\section{Conclusions}

It was observed that student creativity and engagement improved with less structure in the activities, when the assignments allowed for independent exploration. There was always a brief lesson of basic concepts, and a technology demonstration for each new concept. Then the students would be asked to perform an introductory guided task and once completed the instructor can challenge them to go beyond that, usually with open ended design suggestions and freedom to explore. The availability of games with related concepts allowed for differentiation so advanced students remained occupied with alternative activities while the struggling students received the necessary assistance to progress. Students have remained engaged during the camp and have been able to master the concepts to make basic electro-optical system in just a few short days (a total of 16 hours of instructional time). The size of the camp could be scaled up, but 
teaching assistants would need added for balance. To give students a deeper experience the camp could be extended to a fifth day or increase the amount of time in each day. This curriculum is adaptable and can be scaled down or drawn out depending on needs and resources.

\section{References}

[1] "The Global Electro-Optical/Infrared (EO/IR) Systems Market 2018-2028: CAGR is Projected to Grow at 2.98\% - ResearchAndMarkets.com," AP News, 07-Aug-2018. [Online]. Available: https://www.apnews.com/f56ab5e4ac7e4185904ebf8ff4a5b02e. [Accessed: 04-Feb-2019].

[2] "Electro Optical System Market: Global Industry Analysis 2012 - 2016 and Opportunity Assessment; 2017 - 2027," Future Market Insights. [Online]. Available: https://www.futuremarketinsights.com/reports/electro-optical-system-market. [Accessed: 04-Feb-2019].

[3] "17-2199.07 - Photonics Engineers," $O * N E T$ OnLine. [Online]. Available: https://www.onetonline.org/link/summary/17-2199.07. [Accessed: 04-Feb-2019].

[4] "Average Electro Optical Engineer Salary," Payscale.com. [Online]. Available: https://www.payscale.com/research/US/Job=Electro_Optical_Engineer/. [Accessed: 04Feb-2019].

[5] "Electro-Optical Engineer Annual Salary (\$99,680 Avg | Feb 2019)," ZipRecruiter. [Online]. Available: https://www.ziprecruiter.com/Salaries/Electro-Optical-Engineer-Salary. [Accessed: 04-Feb-2019].

[6] Arduino - Introduction. [Online]. Available: https://www.arduino.cc/en/Tutorial/HomePage. [Accessed: 04-Feb-2019].

[7] "Learn Arduino," Adafruit Learning System. [Online]. Available: https://learn.adafruit.com/category/learn-arduino. [Accessed: 04-Feb-2019].

[8] "Spectra Sound," APS Physics. [Online]. Available: https://apsphysics.myshopify.com/products/spectra-sound. [Accessed: 04-Feb-2019].

[9] "Laser Chess ${ }^{\mathrm{TM}}$," Thinkfun. [Online]. Available: https://www.thinkfun.com/products/laserchess/. [Accessed: 04-Feb-2019].

[10] J. A. M. Nijssen,"Using intelligent search techniques to play the game Khet," M.S. Thesis, Dept. of Knowledge Eng., Maastricht Univ., Maastricht, Netherlands, 2009.

[11] A. Mazalek, C. Winegarden, T. Al-Haddad, S.J. Robinson, and C. Wu. "Architales: Physical/digital co-design of an interactive story table," In Proceedings of the 3rd International Conference on Tangible and Embedded Interaction (TEI'09). ACM, New York, 241-248. 2009. doi = http://doi.acm.org/10.1145/1517664.1517716.

[12] A. Wu, D. Joyner, and E.Y. Do, "Move, beam, and check! imagineering tangible optical chess on an interactive tabletop display," Computers in Entertainment (CIE). Vol. 8 No 3 p20 Dec 2010.

[13] "Laser Battle," BoardGameGeek. [Online]. Available: https://boardgamegeek.com/boardgame/24245/laser-battle. [Accessed: 04-Feb-2019]. 
[14] "Khet Wins Infringement Lawsuit Against MGA's Laser Battle," Purple Pawn Game News Across the Board. [Online]. Available: http://www.purplepawn.com/2009/10/khet-winsinfringement-lawsuit-against-mgas-laser-battle/. [Accessed: 04-Feb-2019].

[15] "Laser Maze ${ }^{\mathrm{TM}}$," Thinkfun. [Online]. Available: https://www.thinkfun.com/products/lasermaze/. [Accessed: 04-Feb-2019]. 